Article

\title{
Strategic Networking for Sustainability: Lessons Learned from Two Case Studies in Higher Education
}

\author{
Judith Kahle ${ }^{1}$, Katrin Risch ${ }^{2}$, Andreas Wanke ${ }^{2}$ and Daniel J. Lang ${ }^{1, *}$ \\ 1 Institute for Ethics and Transdisciplinary Sustainability Research, Leuphana University, Universitätsallee 1, \\ 21335 Lüneburg, Germany; judith.kahle@leuphana.de \\ 2 Unit for Sustainability and Energy Management, Freie Universität Berlin, Schwendenerstraße 17, \\ 14195 Berlin, Germany; katrin.risch@fu-berlin.de (K.R.); andreas.wanke@fu-berlin.de (A.W.) \\ * Correspondence: daniel.lang@leuphana.de; Tel.: +49-4131-677-1678
}

Received: 31 October 2018; Accepted: 4 December 2018; Published: 6 December 2018

check for updates

\begin{abstract}
As places where future citizens are educated, knowledge is (co-)produced and societal developments are critically reflected, higher education institutions (HEIs) can play a key role in addressing sustainability challenges. In order to accelerate mutual learning, shared problem understanding, and joint development of sustainable solutions, interinstitutional exchange and collaboration between HEIs is crucial. However, little research to date has focused on institutional HEI networks in the field of sustainability. More specifically, we still understand little about the concrete development, implementation, and adaptation of such networks. This article explores early-stage HEI networks for sustainability from a conceptual and empirical stance in order to develop a framework that facilitates structured descriptions of these networks, as well as to foster cross-HEI learning on their effective performance. It therefore combines insights from an explorative literature review, two case studies and an interactive workshop at the ISCN Conference 2018. As results, we first suggest an analytical framework to facilitate a systematic characterization of HEI networks. Second, by applying the framework to the two case studies, we present and discuss lessons learned on how a single HEI can contribute to establishing a network and how it can utilize its network membership effectively to strengthen its efforts for sustainability.
\end{abstract}

Keywords: higher education institution; networks; sustainability; collaboration; interdisciplinarity; transdisciplinarity; learning; innovation; whole institution approach

\section{Introduction}

Global sustainability problems such as climate change, biodiversity loss, and poverty are leading to major socio-ecological change, prompting us to accelerate joint efforts to achieve a more sustainable and just future [1-4]. Higher education institutions (HEIs), as places where future citizens are educated, knowledge is (co-)produced, and developments are critically reflected, can play a key role in addressing sustainability challenges [5-12]. The term higher education institution (HEI) in Germany usually encompasses research universities, universities of applied sciences, as well as colleges of art and music. In this article, we focus on the first two types of HEIs. Within their different fields of operation such as governance, research, education, campus management, reporting, and transfer (meaning mutual exchange of knowledge, ideas, services, technologies, and experience between HEIs and other societal actors from politics, industry, public sector, and civil society) $[6,10,13,14]$, HEIs provide structures and resources to bring together various kinds of actors and expertise. They allow working on approaches for creating, critically reflecting, testing, and further developing concrete sustainable solutions. As such, HEIs can serve as platforms for theoretical and practical learning for sustainability transformation $[7,10,15]$. 
Embedded in specific geographic, political, and cultural contexts, HEIs provide different approaches and expertise on how to address sustainability challenges. Therefore, interinstitutional exchange, collaboration, and even co-creation between HEIs are crucial, as they allow "for accelerating learning by sharing problem understandings, successful solutions, and important contextual considerations" ([4], p. 749). With regard to a general spectrum of formats of interaction, we consider exchange, collaboration including co-design, co-production, and outreach as relying on two-way-communication. While exchange generally requires little commitment, collaboration requires greater commitment, as well as more active engagement on an equal footing [16]. In this regard, local, national, and international networks allow for a multilateral type of exchange and collaboration between persons, teams, institutes or institutions (so-called "nodes") in the higher education sector [17]. Such HEI networks are often regarded as "vehicles for innovation and improvement in educational systems" ([18], p. 6); as well as a powerful impetus for organizational learning and the development of innovative solutions $[19,20]$.

Networks proceed through consecutive developmental stages, in which they integrate different functions to reach specific benefits [20]. Based on the life-cycle model, Verburg and Andriessen [20] suggest three stages of networks: development, implementation, and adaptation. From a political stance, networks allow institutions such as HEIs and their actors to form new collaborative formats and interest groups [19]. As part of this political function declarations, as well as incentive structures, can be helpful to encourage inter- and transdisciplinary collaboration for sustainability within and across HEIs [8,12]. Furthermore, related to an incentivizing or motivating function, the reference to the network activities may also act as a leverage for a single HEI to move forward with new projects, e.g., in sustainable campus management [19]. This positive effect is closely connected to the psychological function, as institutional, team and individual network members find themselves amongst a group of like-minded HEI actors, working towards similar goals, values, and jointly developed products (e.g., publications in sustainability research, manuals, and best practice-collections as guidance for sustainability managers or policymakers), in or across their institutions-thus allowing individual learning and empowerment $[19,20]$. This is also facilitated by the information function that networks serve. An ever-growing range of face-to-face, as well as virtual exchange and collaboration formats, allows for an information flow across institutions and in many cases hierarchies. These settings also give individuals and groups, representing HEI members in a network, opportunities to acquire new skills from their peers that may not be offered by traditional training schemes [19]. The implicit skills function of networks is increased in international, trans- and interdisciplinary formats of exchange, fostering the intercultural sensitivity and competency of network members $[1,19]$.

Exchange, collaboration, and even co-creation for sustainability is rooted in the comprehensive experience of well-established and large HEI networks, such as the International Association of Universities (IAU, founded in 1950) [21], the Association of African Universities (AAU, founded in 1967) [22], and the Global University Network for innovation (GUNi, founded in 1999) [23]. These networks span up to several hundreds of members from a great number of countries and include sustainability-related objectives in their strategic alignment. Other HEI networks, such the International Sustainable Campus Network (ISCN, founded in 2007) [24] and the Association for the Advancement of Sustainability in Higher Education (AASHE, founded in 2005) gained momentum and large numbers of members from different parts of the world in the past 10 to 15 years. They follow a clear agenda focusing on the contribution of HEIs to sustainable development on the local, regional, national, and international level. Both examples of large HEI networks have clear governance structures and a widely diversified portfolio of instruments available to contribute to sustainability, e.g., regular reports, annual conferences, joint projects, and a spectrum of options to share and spread information among their members and beyond. In addition, a number of smaller HEI networks have been established in the last years in order to work more intensively with a concentrated number of HEI members toward contributions for sustainability, such as the University Alliance for Sustainability (UAS, founded in 2014) [25] and Sustainability at Higher Education Institutions Network (HOCH-N, 
founded in 2016) [13]. In this article, we focus our research attention on hitherto barely investigated early-stage HEI networks for sustainability.

A growing body of literature investigates different formats of inter- and transdisciplinary HEI-collaboration [4], e.g., focusing on international, often bi-lateral research collaborations and co-authorships [26,27], joint education projects $[4,28,29]$, as well as mutual knowledge and first-hand experiential exchange on efforts for sustainable campus management [24]. Other works address different forms of networks from a meta-perspective $[17,20]$. However, little research to date has focused specifically on early-stage networks of institutions in the field of sustainability, especially not from the perspective of single HEIs as members or nodes in such networks. Furthermore, we still understand little about the concrete contributions of single HEIs to the development, implementation, and adaptation, as well as concrete outcomes of such networks for sustainable development.

In this article, we pursue the following objectives: First, we suggest an analytical framework to spur a more structured description and reflection of HEI-networks. Secondly, we adopt this framework to investigate two contrasting cases of HEI-networks for sustainability in greater detail to test its applicability and learn more about structures and processes facilitating or inhibiting networks to meet specific functions. Besides a general comparison on the network level, we do so from the node perspective of a single HEI-network member to facilitate cross-HEI learning on the effective performance of these networks. For each of the two exemplary cases, we focus on a specific aspect of HEI networks for sustainability. On the one hand, we provide insights into how a single HEI-node in a network can contribute to establishing an HEI network. On the other hand, we focus on concrete outcomes for a single HEI as a member in a network for sustainability.

In Section 2, we describe the methodical proceeding we used for addressing the aims of this article. In Section 3, we first present a set of 15 characteristics to allow a structured and detailed description HEI-networks before we apply these characteristics to the two case studies. Section 4 integrates and discusses the results by focusing on lessons learned from the two case studies. These results are complemented by insights from a workshop held at the 12th International Sustainable Campus Network (ISCN) Conference. Section 5 concludes by reassessing the HEI-networks as a contribution to sustainability.

\section{Methods}

To address the two main objectives, this article employed a qualitative research approach combining insights from an explorative literature review, two contrasting case studies and a joint interactive workshop at the ISCN Conference 2018 in Stockholm [30]. We triangulated the insights to (i) identify and test key characteristics for describing HEI networks and (ii) to gain insights into the development, as well as into first impacts of two smaller networks focusing on sustainability.

\subsection{Explorative Literature Review}

An explorative review of the literature from different fields of study was conducted in Google scholar revolving around the terms "networks", "sustainability", and "higher education institutions". In addition, similar terms derived from the literature, such as "collaboration", "internationalization", "partnerships" and "universities", were applied in different search strings to identify further relevant literature. English and German references were considered for the review. Various scholars have already discussed the limitations of literature reviews relying on a single database in general, and relying on Google scholar in particular [31-33]. In fact, no single database provides full coverage of the relevant literature [31]. For the explorative literature review at hand, we did not strive for a full coverage of the literature. Instead we aimed for a selection of scientific literature from different academic disciplines to gain a broad view on networks as the overall basis for the analytical framework. Despite its flaws discussed in the literature, e.g., the lack of reliable advanced search functions [32], we still decided to rely on Google scholar because of its high coverage, especially in relevant fields for this article, such as business, economics and management, humanities, literature and arts, as well as the 
social sciences [33]. We analyzed the obtained literature qualitatively with the intention to inductively extract characteristic features that capture the specific traits of networks [34]. The collected text junks in form of short paragraphs, sentences, and parts thereof, as well as key words were clustered according to similar or related content. In a next step, appropriate terms were developed or gained from the literature itself for each of the clusters constituting the set of network characteristics. The set of characteristics developed in this way, was then put into a logical order and specified via short descriptions and/or illustrative examples (see Table 1). The characteristics represent an essential first result of this article which were subsequently applied to two case studies of HEI networks for sustainability in order to structure our empirical and experiential findings and to test the applicability of the characteristics.

\subsection{Case Study}

For the empirical part of our study, we applied a case study approach [35-37]. We focused on two HEI-networks that both employ a whole institution approach to facilitate and institutionalize HEI engagement for sustainable development: (a) Network of Higher Education Institutions for Sustainability (HOCH-N), a national consortium of German universities and universities of applied sciences; and (b) University Alliance for Sustainability (UAS), an international network of five partner universities from Germany, Israel, Canada, China, and Russia. Both cases imply a rich learning potential for whole HEIs to individual HEI-actors, as they follow similar aims and approaches but span different geographic scales and rely on different instruments and strategies for their implementation. As the authors play crucial roles as co-founders, network managers and members, conducting self-reflexive case studies and presenting them at the ISCN Conference 2018 was viewed as important steps to take stock and seek constructive feedback for potential adjustments.

For each of the case studies, a self-reflexive process was implemented from the perspective of the two German universities represented by the authors: Freie Universität Berlin and Leuphana University Lüneburg. For doing so, information on involved actors, selected and applied instruments, as well as strategies, established structures, and first outcomes including benefits and obstacles, were collected, respectively. Based on the conceptual framework developed from the literature, the information was structured and documented in order to allow the narration of a context- and case-specific story [35]. On the one hand, the tabular short descriptions of each network formed the point of departure for an internal systematic reflection of our own empirical research within the HOCH-N network. On the other hand, we relied on practical experiences, as well as personal observations of processes and dynamics within HOCH-N and UAS network. The collected information was internally discussed with regard to the strengths and weaknesses of each network's structures, processes and first outcomes as a contribution to sustainability.

\subsection{Interactive Workshop at the ISCN Conference 2018 in Stockholm on 12th June}

During the 12th ISCN Conference, the authors of this article jointly conducted an interactive workshop on strategic networking among HEIs for sustainability. Both the workshop organizers and participants represented different status groups of several HEIs. In total, 15 people from eight countries participated in the interactive session. The participants came from a wide range of professional backgrounds: five researchers; four (senior) sustainability managers; one PhD student, two students, and one participant represented a non-governmental organization. The professional backgrounds of two persons could not be specified. In total, nine men and six women participated. We are aware, that the participants most certainly did not reflect a representative sample of international HEI actors engaged in networking for sustainability. Nevertheless, the overall ISCN conference context can be viewed as a pre-selective filter of international HEI stakeholders who are aware of and also actively engaging in HEI networking for sustainability. Another filter is the individual motivation to engage, not in one of the parallel workshops, but in this specific workshop on HEI networks for sustainability pointing to the participants' personal commitment and expertise in the 
topic. Subsequently, the small sample encompassed an impressive variety of participants in terms of degree of academic qualification, field of action, and duration of professional experience, as well as geographic origin of their home HEI. This group has discussed lively and actively contributed its diverse expertise within the workshop. Although not representative, we decided to incorporate the valuable contributions into this article in order to enrich the discussion of HEI networks for sustainability based on two contrasting cases and the scientific literature in the field. The authors briefly introduced each case study in order to provide inspiration and a shared starting point for the subsequent interactive part. Workshop participants were engaged in two rounds of small group discussions, in order to share and collect their expectations and experiences with HEI-networks for sustainability, as well as to debate leverage points and practices to strategically advance such networks. Afterwards, the outcomes from the group discussions were recorded, supplemented, and restructured to increase intelligibility. Finally, they were used to complement the lessons learned from the two case studies on HEI-networks for sustainability, as discussed in Section 4.

\section{Results}

\subsection{Characterizing HEI-Networks for Sustainability}

Table 1 presents the analytical framework to characterize HEI-networks based on the explorative literature review, as well as insights from our personal experience as co-founders of two HEI-networks for sustainability.

The 15 characteristics represent an analytical framework to systematically differentiate between structure (characteristics \#1-9), processes (characteristics \#10-13), and context (characteristic \#14) which are unique to each network and are already existing or aspired outcomes of the network activities (characteristic \#15). They first specify which individual and/or groups of actors-from a specific region and supported by certain resources-are collaborating with each other for a specific topic in order to jointly strive for common goals. Secondly, they specify how this collaboration is organized and proceeding along the different developmental stages of a network. Thirdly, the societal context is covered in which a network is embedded. Finally, the results and impacts a network can unfold are covered. The set of characteristics is designed to make essential features of HEI-networks explicit for both members and external stakeholders alike. The characteristics were derived from the scientific network and collaboration literature of various academic disciplines. They therefore do not focus on networks for sustainability in particular but on HEI networks in general. By adopting the characteristics to two exemplary HEI networks for sustainability, we investigated their applicability to the context of sustainable development in the higher education sector. According to the literature used, all identified features were included in the analytical framework for structured descriptions of HEI networks. Our goal was to introduce a literature-based comprehensive set of characteristics that is, at the same time, as specific and general as possible. As to our knowledge, such a framework for HEI networks has not been introduced before. Due to the limited literature bases, we are aware that our synthesis may have overlooked single network features. However, the 15 characteristics can serve as a means to derive commonalities and differences between networks, thus informing potential future network members, but also allowing a network to be systematically located within the landscape of other networks.

To make the 15 characteristics more tangible, they are applied, slightly adapted, and discussed in the subsequent Sections 3.2 and 3.3 with regard to the two exemplary HEI-networks for sustainability in this article- $-\mathrm{HOCH}-\mathrm{N}$ and UAS. 
Table 1. 15 characteristics of networks among organizations such as higher education institutions (HEIs) based on an exploratory scientific literature review.

\begin{tabular}{|c|c|c|c|}
\hline & Characteristic & Specification & References \\
\hline 1. & Geographic scope & $\begin{array}{l}\text { Dispersion of network members on a local, regional, national, } \\
\text { international level. }\end{array}$ & {$[1,20]$} \\
\hline 2. & Subject & Overall topic a network focuses on. & [1] \\
\hline 3. & Objective & $\begin{array}{l}\text { Overall objective or spectrum of objectives a network pursues, } \\
\text { e.g., building institutional capacity, jointly developing } \\
\text { educational programs, staff exchange, etc. }\end{array}$ & {$[4,20,26]$} \\
\hline 4. & Resources & $\begin{array}{l}\text { Financial, institutional, and human resources a network has at } \\
\text { hand to work with. }\end{array}$ & {$[1,10,26]$} \\
\hline 5. & Composition & $\begin{array}{l}\text { Clarifies how many and which actors (individuals up to } \\
\text { whole HEIs) are part of a network, as well as who is } \\
\text { collaborating with whom. }\end{array}$ & {$[1,4,20,26]$} \\
\hline 6. & $\begin{array}{l}\text { Organizational structure and } \\
\text { role of leadership }\end{array}$ & $\begin{array}{l}\text { Specifies how a network is internally structured and operating } \\
\text { in terms of role distribution, decision-making power, } \\
\text { and hierarchy. }\end{array}$ & {$[20,38]$} \\
\hline 7. & Open/closed & $\begin{array}{l}\text { Networks either encompass a fixed number of members or are } \\
\text { open to enroll new members. }\end{array}$ & [20] \\
\hline 8. & Heterogeneity/homogeneity & $\begin{array}{l}\text { Diversity aspects such as ethnicity, gender, language, etc., } \\
\text { relevant in a network, as well as different working cultures } \\
\text { and norms relating to hierarchy and status within and } \\
\text { between HEIs. }\end{array}$ & {$[1,7,26]$} \\
\hline 9. & Degree of formalization & $\begin{array}{l}\text { Specifies how far structures and processes of a network are } \\
\text { institutionalized, e.g., via defined memberships, formal rules } \\
\text { of composition, interaction and communication. }\end{array}$ & {$[1,20,26]$} \\
\hline 10. & Type(s) of collaboration & $\begin{array}{l}\text { Specifies the organizational type through which collaboration } \\
\text { is implemented in a network, e.g., via joint teaching, } \\
\text { collaborative research, visiting students and staff, } \\
\text { joint institutes. }\end{array}$ & {$[1,4,26]$} \\
\hline 11. & $\begin{array}{l}\text { Mode of interaction and } \\
\text { communication }\end{array}$ & $\begin{array}{l}\text { Face-to-face or virtual exchange and collaboration via } \\
\text { application of information technology. }\end{array}$ & {$[1,20,26]$} \\
\hline 12. & Developmental stages & $\begin{array}{l}\text { Networks develop over time by going through consecutive } \\
\text { stages from birth to death (life-cycle perspective) or from } \\
\text { low-to-high levels of maturity (evolutionary perspective). }\end{array}$ & {$[20,26]$} \\
\hline 13. & Ethos & $\begin{array}{l}\text { Specifies the social frame in which a network is embedded, } \\
\text { e.g., encompassing working atmosphere, joint identity, } \\
\text { trust, commitment. }\end{array}$ & {$[1,17,20,26]$} \\
\hline 14. & Context & $\begin{array}{l}\text { Political, cultural, and economic context, as well as societal } \\
\text { structures and processes a network is embedded in. }\end{array}$ & {$[1,8,12,26]$} \\
\hline 15. & Outcome & $\begin{array}{l}\text { Results and impacts a network has for all or some of its } \\
\text { members, for actors, structures, and processes in- and outside } \\
\text { the network. }\end{array}$ & {$[1,4,7]$} \\
\hline
\end{tabular}

\subsection{Learning How to Effectively Contribute to the Development of an HEI-Network for Sustainability: The Case of the HOCH-N Network}

In this section, we shed light on the practical, conceptual, and empirical contributions of a single university to help establish a national HEI network for sustainability. The case study at hand, focuses on the network "Sustainability at Higher Education Institutions (HOCH-N)" especially from the perspective of Leuphana University Lüneburg in Germany, as one institutional node in this network. We specify the characteristics of the network and summarize them in Table 2, present its main governance structures, as well as the strategies that Leuphana University concretely contributed to the development of the HOCH-N network. Contributions were made on three different levels, national, single HEI-level, and research group level, and were examined concerning encountered challenges 
and coping strategies that were developed. Even though the insights related to $\mathrm{HOCH}-\mathrm{N}$ as a young network might partly seem to be obvious, we think they provide valuable points for reflection for researchers with little experience in networking but also to some extent for more experienced actors.

\subsubsection{Fostering Sustainability in Higher Education via National Collaboration}

In 2015, the Global Action Program on Education for Sustainable Development (ESD) resumed the Decade of ESD by the United Nations Educational, Scientific, and Cultural Organization (UNESCO). This program particularly addresses Sustainable Development Goal \#4 of the United Nations on education as one essential leverage point to promote sustainable development [39]. It is this top-down driving factor which motivated the German Federal Ministry of Education and Research to intensify its funding for sustainability projects in the education and higher education sector via its funding program "Research for Sustainable Development (FONA)" which aims to implement the Global Action Program on ESD on a national level. Another driving factor was the sustainability codex resolved by the German Council for Sustainable Development in 2011. The HOCH-N project set out to adjust this codex, which was originally dedicated to foster sustainable development in the private sector to the context of higher education institutions. A more bottom-up driving factor for the HOCH-N project and network was the wish for a joint effort to conflate the multitude and diversity of approaches to sustainability by an increasing number of HEIs across Germany. As a consequence, the joint research project "Sustainability at Higher Education Institutions: develop - network - report (HOCH-N)" was launched in 2016; funded by the German Federal Ministry of Education and Research. In HOCH-N, researchers from 11 German HEIs are collaborating with each other to integrate already existing expertise and future developmental potential of HEIs to contribute to sustainability. German HEIs involved in the HOCH-N project are: Bremen University, Duisburg-Essen University, Eberswalde University for Sustainable Development, Freie Universität Berlin, Hamburg University, Leuphana University Lüneburg, Tübingen University, Ludwig-Maximilian-Universität Munich, Technische Universität Dresden, Vechta University, Hochschule Zittau-Görlitz. The overall lead in this project lies at Hamburg University. The management and coordination of the HOCH-N network, representing one specific objective of the underlying joint research project, is led by Hamburg and Bremen University. Within the HOCH-N project and its network, an interdisciplinary team of sustainability-oriented research experts from Leuphana University is actively involved.

With the launch of the project, also the design and planning phase, as well as first steps to establish the HOCH-N network were taken. Acknowledging already existing HEI-networks for sustainability (i) on the federal state and international level; (ii) between a small selection of HEIs and other research institutions; as well as (iii) spanning just one specific group of HEI-stakeholders (e.g., sustainability managers), the HOCH-N network embarked on a national scope, bringing together various groups of HEI stakeholders from deans to students, from researchers and lecturers to technicians and administrators. Therefore, researchers and practitioners from other German HEIs outside HOCH-N were specifically invited to become members of the open $\mathrm{HOCH}-\mathrm{N}$ network in order to share their expertise and contribute to the overall goal of $\mathrm{HOCH}-\mathrm{N}$. That is to promote sustainable development across the different fields of action at German HEIs. For this, available expertise and established approaches how to consequently reflect upon and integrate sustainability into research, teaching, governance, transfer, campus management and reporting, were collected and visualized. In HOCH-N, making sustainability related scientific and practical knowledge explicit and accessible is considered a basic condition to increase awareness, facilitate and accelerate mutual exchange, learning and interand transdisciplinary collaboration for sustainability within and across German HEIs. In addition, via inviting new members to the network and implementing joint workshops on sustainability-oriented topics in all fields of action of an HEI, HOCH-N aims for strengthening the commitment among HEI-stakeholders to reflect, develop and implement sustainability measurements on campus, as well as bolstering existing bi- and multilateral bonds between German HEIs, and especially to establish new 
ones. Within the first two years, five HEIs and 163 individual actors from 101 German HEIs joined the HOCH-N network.

\subsubsection{Governance: Organizational Structures and Role of Leadership}

The HOCH-N network is still a young network, currently in a transition between its development stage on one hand and its active stage on the other. During the development stage, the collaborative ties among the eleven HEIs, were strongly formalized, e.g., via the formulation of a shared overall goal, a clear distribution of tasks and roles documented in the joint project proposal, the overall project lead assigned to Hamburg University, the central management of the HOCH-N network assigned to Hamburg University and Bremen University, regular face-to-face and virtual meetings for interdisciplinary exchange and collaboration, an online platform to share documents and reporting duties with regard to current research progress and intermediate results in order to seek internal feedback, as well as feedback from the advisory board and the Federal Ministry of Education and Research, etc.

Following a whole institution approach, the project encompassed six working packages dedicated to the different fields of action of HEIs: research, teaching, governance, transfer, reporting, and campus management [14]. In each of the working packages, two HEIs collaborated with each other respectively, thus enabling new bilateral research partnerships for sustainable development. In addition, regular joint workshops across the working packages allowed multilateral knowledge exchange, mutual trust building and learning, as well as collaboration on joint products, such as a shared understanding of "sustainability", joint scientific publications, and practical guides.

On behalf of the formalization of the wider HOCH-N network-beyond the 11 HEIs-basic structures were established, such as a project's website, an online map giving an overview of the number, distribution, and sustainability-related expertise of the network members, a set of admission criteria for potential future members, etc.

\subsubsection{Instruments to Develop the HOCH-N Network}

As outlined above, establishing the HOCH-N network was centrally managed by an interdisciplinary team of sustainability-oriented researchers at Hamburg and Bremen University. At the same time, each of the other nine HEIs involved in the HOCH-N project were asked to actively support this early stage of the network. In the following, we provide insights on how Leuphana University Lüneburg concretely contributed to setting up the HOCH-N network, which obstacles occurred, and which coping strategies were developed. Finally, we reflect upon expected outcomes for Leuphana University as soon as the HOCH-N network fully switches from the initial development to the active implementation stage.

\subsubsection{National Level}

In order to reach out to the wider community of sustainability-oriented stakeholders at German HEIs, the research group at Leuphana University decided to combine the invitation to the network with an inquiry to a nationwide online questionnaire on sustainability-oriented research. We contacted the vice presidents of the 399 HEIs in Germany via email, briefly informed them about the network, included a link to its online presence and cordially invited the vice presidents to become members, as well as to forward the invitation to sustainability-oriented researchers/stakeholders at their institution. Shortly after the invitations were sent to the vice presidents, inquiries to become network members increased. Although new members were not asked how they got to know about the open $\mathrm{HOCH}-\mathrm{N}$ network, it is likely that there was a causal connection to the invitation via email.

We also collected a list of already existing sustainability-oriented networks among different status groups of German HEIs and invited the hosts to spread the word and to become a member of the $\mathrm{HOCH}-\mathrm{N}$ network. With this, we intended to foster exchange and collaboration across already existent 
HEI-networks for sustainability which focus on single HEI status groups, are located on a regional to federal state level, or are dedicated to just one or two fields of action.

\subsubsection{Level of Single Higher Education Institution}

Another approach to support the acquisition of members in the HOCH-N-network was to spread information on the network and gain new members at Leuphana University itself. Due to technical limitations a maximum of seven to eight individual stakeholders of one HEI could become members. Thus, we decided for a targeted selection of potential future members, up to three from each status group, HEI-management and administration, research and teaching, as well as the student body. Additionally, we considered the specific expertise and hitherto observable commitment to engage for sustainable development, as well as a person's continuance in office. We also minded a gender balance and spectrum of academic qualification among the potential members.

The selected stakeholders were contacted via email and/or personally in order to invite them to the network. Support was given to create and establish individual network profiles as the entrance ticket to the network. Here we faced organizational challenges as different stakeholders required different contact strategies. Often several emails and/or personal contacts were necessary in a time-consuming and prolonged process due to high workload of the contacted persons, the generally voluntary character of networking activities and insecurity about the relation of individual effort and advantages of a membership. At an interval of several weeks, friendly reminders were sent out and the opportunity given to discuss open questions and potential benefits via email or personally. The given information was finally forwarded to Hamburg University and incorporated into the online map of the network.

\subsubsection{Level of Research Group}

The main contribution to the development of the HOCH-N network was to work up a practical guide in collaboration with sustainability-oriented researchers from Ludwig-Maximilian University Munich. The guide focuses on research as one of the six fields of action addressed in the joint project $\mathrm{HOCH}-\mathrm{N}$ and is based on conceptual and social empirical research. Its goal is not to provide an instant recipe on how to conduct ideal-typical sustainability-oriented research. With regard to the diversified landscape of such research, the guide provides a spectrum of hands-on information and examples to demonstrate different options of how research can be designed and implemented as a concrete contribution to sustainable development. The guide thus provides inspiration and orientation for future sustainability-oriented research at German HEIs [40].

More specifically and based on an online-questionnaire implemented at all 399 HEIs in Germany the guide provides insights into the current landscape of sustainability-oriented research at German HEIs. Three-hundred-and-fifty-eight HEI actors, mostly researchers but also technicians, administrators, and students from about 100 German HEIs participated in the survey.

We are aware that the data is not representative for sustainability-oriented research at German HEIs in total. One of the challenges was to develop an approach to identify researchers as sustainability-oriented or not. We decided to rely on self-identification. Thus, researchers who may conduct sustainability-related research without calling it that were not reached with this strategy. Another challenge was to develop a contact strategy to reach out to the sustainability-oriented research community at German HEIs effectively. As there is no database available which entails an overview of all researchers at German HEIs, we sent the questionnaire via e-mail to the vice presidents at all German HEIs via e-mail and kindly asked them to forward it to relevant stakeholders at their home institution. In addition, we sent the questionnaire to the contact persons of regional sustainability-oriented HEI or research networks and asked to spread it among the network members. On the one hand, both contact strategies had the potential to reach out quickly and with limited effort to a great number of sustainability-oriented researchers at German HEIs. On the other hand, both strategies depended on the collaborative willingness of a rather small number of key actors. 
However, the collected data allows a first impression of the current landscape of sustainabilityoriented research foci, trends, and gaps. The data thus contains valuable information for sustainabilityoriented researchers and whole research institutions on how to locate their own work within the current landscape and strategically plan their future sustainability-oriented research including research collaborations.

In addition, the guide provides application-oriented information on how to concretely initiate, implement, and/or expand sustainability-oriented research at the home HEI. Based on a narrative literature review, three ranges of action were identified as practical leverages to facilitate sustainability-oriented research, i.e., research setting, research process, and academic qualification. This conceptual contribution was validated and completed via semi-structured telephone interviews with 27 stakeholders from research services, research and teaching, as well as sustainability offices from seven selected German HEIs. Subsequently, a fourth range of action on "networking" was added. Furthermore, exemplary instruments and strategies for each of the four ranges were developed from the interviews with researchers from HEI network members, as well as illustrated by tried and tested practical examples.

Parallel to the challenges in the survey, we adapted the self-identification strategy to select our interview partners by relying on explicitly sustainability-related information of potential interview partners presented on the website of their home institution. Another challenge was to develop a clearly structured and appealing form of presenting the spectrum of collected instruments and practical examples for an interested audience. For this, we searched for inspiration in practical guides such as the Green Guide for Universities [41], as well as collegial feedback from within the HOCH-N project.

As a side effect of the survey and interviews, a comprehensive number of stakeholders from German HEIs who were involved in the quantitative and qualitative data collection were informed about the underlying joint research project, as well as the HOCH-N network, thus increasing its visibility.

\subsubsection{Expected Outcomes at Leuphana University Lüneburg}

After contributing to the development of the HOCH-N network, Leuphana University is looking forward to continued active engagement in and concrete benefits from the network in the near future. One of the next steps is to test and, if necessary, refine the collected instruments and strategies at other HEIs in the HOCH-N network. This is planned as a multilateral collaboration between Leuphana University and additional HEIs. We, therefore, expect to further strengthen the ties between HEI-nodes in the HOCH-N network, as well as to stir inspiration and learning at Leuphana University itself to further develop solution-oriented sustainability research.

\subsection{Learning How to Leverage Strategic Benefits from an HEI-Network for Sustainability: The Case of the UAS Network}

In this section, we share insights on how a single HEI can leverage positive outcomes for its sustainability activities from networking internationally. The case study refers to the "University Alliance for Sustainability" network, of which Freie Universität Berlin was initiator and co-founder. The authors of this section contributed actively to building and consolidating the network as UAS program leader and network manager and provide a critical self-reflection of lessons learned. It will be shown how the step-by-step establishment of the network became the basis for the internal networking of sustainability-related stakeholders and the initiation of new teaching formats at Freie Universität Berlin. In the following, we specify the characteristics of our network including a concise overview in Table 2, introduce governance structures, instruments, and assess the effects on sustainability related structures and processes at Freie Universität Berlin. Insights gained are reflected against challenges and developed coping strategies. 


\subsubsection{Fostering Sustainability via International Collaboration}

Considering the global scope of the topic of sustainability and the international research community universities are embedded in, there is tremendous potential for international collaboration. This mindset led to the foundation of the "University Alliance for Sustainability" (UAS) in 2015. The UAS network with Freie Universität Berlin as one of its nodes is based on the bilateral strategic university partnerships that have evolved from long-standing university partnerships, including the Peking University (partner since 1981, strategic partner since 2011), Hebrew University of Jerusalem (partner since 1986, strategic partner since 2011), St. Petersburg State University (partner since 1968, strategic partner since 2012), and the University of British Columbia (partner since 2012, strategic partner since 2014). Establishing strategic partnerships with leading research universities worldwide is part of the internationalization strategy of Freie Universität Berlin. The objective of these alliances is to allow for comprehensive networking and collaboration on all university levels, i.e., regarding the sustainable support of young researchers, the initiation and implementation of innovative research co-operation, the development and establishment of future-oriented teaching, and the exchange of researchers, students, and staff. When selecting strategic partners, Freie Universität Berlin takes into account the diversity and intensity of existing contacts, as well as the potential for future cooperation.

It is the objective of the UAS to foster an inter-university and transdisciplinary dialogue, connecting university stakeholders in the field of sustainability. Following a whole institution approach the partner universities leverage the relationships and collaborations they built in various disciplines to address sustainability challenges in research, teaching, campus management, and transfer. This implies the placement of sustainability issues in all structural and thematic entities of the universities, going beyond the usual segmentation of an HEI. The UAS partners developed a high degree of formalization with an institutionally rooted governance structure aimed to ensure effective management of the network and a successful transfer of best practice examples between institutions.

\subsubsection{Governance: Organizational Structures and Role of Leadership}

Looking back, the clear structure of the decision-making bodies and their anchoring within the leadership level, ensured the high visibility and institutional support given to the network from the outset. The Network Board is the highest decision-making body and comprises vice presidents or prominent academic representatives from all partner universities.

At Freie Universität Berlin a Steering Committee is responsible for the strategic development of the network. It consists of the vice president for international affairs and the former vice president for research and sustainability in teaching, the UAS program leader and network manager, as well as a representative of the Center for International Cooperation at Freie Universität Berlin. This composition ensures that decisions are reflected in the overall internationalization strategy of Freie Universität Berlin, in addition to the day-to-day needs of the UAS network development.

The network activities are coordinated by the Unit for Sustainability and Energy Management that is in charge of steering sustainability management at Freie Universität Berlin. The operational management aspects of the UAS are largely dealt with by the network manager at Freie Universität Berlin and the respective coordinators at the partner universities. As the crucial contact persons for incoming fellows, they ensure the smooth proceeding of the exchange program between the partner universities. In addition, they facilitate networking in research and campus management at their home university by keeping track of stakeholders involved, supporting joint project proposals, and research triggered in the network.

\subsubsection{Instruments of Implementation}

The UAS mobility program offers exchange options for faculty, staff, and students for research, study or internship stays at the partner universities. Since its initiation, more than 240 individuals have actively participated in the program and evaluated their stays in fellow reports, which are 
openly accessible on the UAS website. An evaluation of the UAS fellows showed that-despite the open application system and incremental network growth - there is a nearly even distribution of male and female participants ( $47 \%$ male, $53 \%$ female). In terms of stakeholder groups funded, the distribution is also relatively even: $36 \%$ senior researchers, $22 \%$ junior researchers, $20 \%$ students, and $22 \%$ administrators. The slightly higher number of senior researchers resulted from the numerous research workshops and strategy meetings in the UAS network. Freie Universität Berlin received most incomings from the partner universities $(52 \%)$, which is due to funding requirements and the workshops, as well as Spring Campus Conferences held in Berlin. Freie Universität Berlin's outgoings went to University of British Columbia (18\%), Peking University (14\%), Hebrew University of Jerusalem (9\%), and Saint Petersburg State University (7\%). A total of 410 participants attended the three Spring Campus Conferences from 2016-2018. About half of them came from Freie Universität Berlin. Of these, more than a third were students and $\mathrm{PhD}$ students. This transparent monitoring of the fellow network helped to build on existing contacts and projects, as well as map the network's development. Reports are evaluated by the network manager, who also maintains a database of people involved in the bilateral collaborations. This overview, combined with proactive communication including a large number of personal conversations about the UAS, significantly contributed to the incremental development of the network, by allowing the linking of researchers at the partner universities and mutual trust building.

Networking in the fields of teaching and campus management is facilitated by incubator workshops aimed at exchanging best practices, developing joint projects, and offering peer-to-peer training opportunities. The joint research, exchange, and outreach activities are addressed by the annual Spring Campus Conferences held at Freie Universität Berlin. During these events, UAS partners showcase and discuss their research and projects in teaching and campus management with an international audience. From 2015 to 2018, the UAS network facilitated three Spring Campus Conferences, two Teaching and five Management Incubators, as well as numerous bilateral research workshops.

The participation of key stakeholders from each partner university in the workshops and conferences largely depended on three factors:

(1) Contacts established during research stays through the mobility program;

(2) Invitations by the coordinators at the respective partner university or the network manager in Berlin;

(3) Calls for contributions, triggering the participation of experts who have not been previously involved in the UAS.

Looking back, the first two approaches proved to be most effective in addressing high-level researchers and senior management staff, who contributed established research or best practice examples.

The UAS receives funding from the German Academic Exchange Service sponsored by the Federal Ministry of Education and Research from 2015 to 2020. This funding contributed significantly to the successful foundation of the network, as it covered the mobility program and the position of the UAS network manager. In order to set the course for the years to come, a Future Lab will be held in late 2019. This will bring together representatives of all UAS partners to carry out an evaluation and to discuss the prospective nature of the partnership for the subsequent years. To ensure continuity, the Executive Board of Freie Universität Berlin has decided to permanently assign the UAS network manager position.

\subsubsection{Outcomes at Freie Universität Berlin}

The UAS network works with a detailed milestone and measurement plan, which focuses on the aforementioned mobility program, conferences, and incubators. Regular reporting duties to the governance bodies of the UAS and the donor also ensure the continuous reflection and evaluation 
of measures taken and their respective outcomes. Already in the start-up phase, the partners have defined which goals they aim to achieve in the first four years of the network collaboration (2015-2018).

At the end of the first round of funding, it can be concluded that the network initiated the establishment and deepening of manifold research and teaching projects at UAS partner universities. Fostering these is an ongoing process. Planned results of UAS include:

(1) Building an international sustainability researchers' network;

(2) Fostering education for sustainable development including cross-HEI curricula development;

(3) Embedding sustainability in the overall management and campus of each partner institution.

In contrast to the intended network results, the UAS' whole institution approach, and moreover, the cross-sectional theme of sustainability, decisively contributed to radiating results in a wide variety of areas. This is also reflected by the network's claim to involve and address all stakeholders and entities of the university. Therefore, results in the field of sustainability did not only affect the work environments of researchers or lecturers but also clearly addressed the overall management and administration of the network member institutions. In addition, the international collaboration sparked a variety of opportunities for additional impacts and initiatives. They essentially resulted from the fact that the process of establishing the international network became increasingly important for internal networking at Freie Universität Berlin. The incremental development of the UAS allowed the network management to embrace and support these spin-offs. In the following, we will specifically reflect on the interdependent developments in the area of teaching at Freie Universität Berlin.

The collaboration in the UAS has been an important impetus for strategic sustainability projects at Freie Universität Berlin. The Unit for Sustainability and Energy Management that is in charge of steering the sustainability management at Freie Universität Berlin and coordinating the UAS, was able to leverage the attention sparked by the network activities and the best practices presented by the partners to advance internal sustainability activities at Freie Universität Berlin. While not being an explicit goal, this was paramount for the central UAS network management at Freie Universität Berlin. The overall aim of deepening the existing collaborations of the partner universities with the normative goal to foster sustainability, was also a trigger to push innovations in the field at Freie Universität Berlin. The UAS network proved to be a door opener for sustainability issues within the university. This was particularly evident in the areas of research and teaching. The interdisciplinary and international design of UAS allowed addressing researchers in all faculties of the university. Personal meetings to introduce the network and respective funding opportunities of the exchange program, conversations on leadership level, as well as networking opportunities during the UAS events, sparked follow-ups with professors and largely contributed to mapping the existing sustainability-related research at Freie Universität Berlin. It also facilitated the dialogue on sustainability and raised awareness for the topic on campus. In this respect, the governance decision to anchor the UAS project in the Unit for Sustainability and Energy Management at Freie Universität Berlin with direct contacts to the Executive Board and a wide range of university contacts has proven to be beneficial.

An evaluation of the milestone plan revealed that a significant number of planned results have been achieved by UAS. However, the network management and members were confronted with a range of challenges and obstacles which led to essential lessons learned. While the partners embraced the whole institution approach, it remained a challenge to address overarching sustainability projects in the segmented structure of Freie Universität Berlin. With regard to interdisciplinary sustainability research projects, it became clear that such a collaboration across academic disciplines is often proclaimed valuable; however, most researchers have not yet developed routines, accordingly. In the UAS-context, this needed to be practiced, especially in terms of creating mutual awareness of and integrating different disciplinary languages. In regards to the teaching collaboration in terms of joint courses and degree programs, the UAS university stakeholders learned that taking small, incremental steps was the most fruitful strategy. They also understood that setting up international teaching collaborations requires strong and continuous administrative support from the respective home HEIs, time intensive input 
from involved teaching personnel, as well as a clear foundation in the local study regulations. The last factor includes considerations of credit recognition and language of instruction. Here, the network management learned that these processes often need more time than expected. In the beginning activities should thus focus on the exchange of best practices, short-term lectureships, and individual joint courses to facilitate the development of joint programs and degrees in the long-run.

One area where the additional impacts of the international networking (in that scope) became particularly evident at Freie Universität Berlin is the area of teaching. The exchange on curricula, didactics, methods, and resources in the Teaching Incubator contributed to the development of an interdisciplinary curriculum "Sustainable Development" in the General Professional Skills courses at Freie Universität Berlin, which is mandatory for undergraduate students. The idea to establish such an inter- and transdisciplinary teaching format open to students from different faculties took further shape and was driven by the international UAS network. The exchange provided an overview of best practices at all partner universities, including projects, courses, methods, and virtual resources. It brought together key stakeholders from teaching and curriculum development at Freie Universität Berlin, who had the chance to connect with colleagues at partner universities.

Inspired by the international best practice examples, members of the working group "teaching" of the sustainability steering committee at Freie Universität Berlin integrated these insights and tailored a curriculum to the specific needs of students at Freie Universität Berlin. Actively integrating the leverage points provided by the international collaboration, contributed to the rapid realization of the project in only two semesters. The exchange in the UAS network, as well as working towards success with the network partners, strengthened their awareness for the sustainability discourse, as well as for the support provided by the FUB top management and created opportunities for sustainability-related innovation. Besides a strong commitment from the FUB leadership, the international network, as well as reporting obligations to the donor facilitated swift implementation of the new competence area "Sustainable Development". As already indicated, the double responsibility of the Unit for Sustainability and Energy Management for the UAS network, as well as for the sustainability management at Freie Universität Berlin, played a key role for the internal advancement of sustainability efforts at FUB from a governance perspective. As the Unit is also in charge of the coordination of the new teaching format it was able to optimally interconnect both processes.

Additionally, the idea to generate a "Sustainability Toolbox" was driven by the UAS network as a whole. The open source toolbox attempts to realize a joint digital teaching and learning platform for the UAS partners and provides sustainability-related expertise to an interested public. Additionally, it aims at facilitating a blended learning approach in on-site courses at the UAS partner universities. Embracing the potential of digitalization in on-site teaching, cross-HEI teaching cooperation and active involvement of the university community in building the toolbox, brought new momentum to the network collaboration. In terms of sustainability, this platform should help to foster the virtual mobility of students and teaching staff, as well as to increase the internationalization of the teaching curricula on sustainability, by including content provided by professors involved in the UAS network.

Based on the detailed case stories of the HOCH-N and UAS network outlined above, Table 2 summarizes and contrasts their main commonalities and differences in a structured overview. 
Table 2. Structured overview of the two exemplary HEI-networks for sustainability based on the 15 characteristics derived from the literature (October 2018).

\begin{tabular}{|c|c|c|c|}
\hline & Characteristic & HOCH-N & UAS \\
\hline 1. & Geographic scope & National & International \\
\hline 2. & Subject & \multicolumn{2}{|c|}{$\begin{array}{l}\text { Sustainable development in all areas of HEIs including governance, research, teaching, campus management, and outreach, as well as } \\
\text { reporting activities }\end{array}$} \\
\hline \multirow{4}{*}{3.} & \multirow{4}{*}{ Objective } & \multicolumn{2}{|c|}{ Foster contribution of network members and the network as such to sustainable development by: } \\
\hline & & $\begin{array}{l}\text { Strengthening exchange, collaboration, joint learning, mutual } \\
\text { inspiration across HEIs for sustainability }\end{array}$ & $\begin{array}{l}\text { Strengthening existing strategic partnerships in the area } \\
\text { of sustainability }\end{array}$ \\
\hline & & $\begin{array}{l}\text { Contributing to the discourse of sustainability by inter- and } \\
\text { transdisciplinary research }\end{array}$ & $\begin{array}{l}\text { Contributing to the discourse of sustainability by developing joint } \\
\text { research and teaching projects }\end{array}$ \\
\hline & & $\begin{array}{l}\text { Disseminating research findings as scientific publications, practical } \\
\text { guides and best practices within and beyond the network }\end{array}$ & $\begin{array}{l}\text { Disseminating research findings and best practices at UAS } \\
\text { Conferences, as scientific publications and in UAS working } \\
\text { paper series }\end{array}$ \\
\hline \multirow{3}{*}{4.} & \multirow{3}{*}{ Resources } & \multicolumn{2}{|l|}{ Inter- and transdisciplinary sustainability-oriented research expertise } \\
\hline & & \multirow{2}{*}{$\begin{array}{l}\text { 2016-2020: Funding by German Federal Ministry of Education } \\
\text { and Research }\end{array}$} & $\begin{array}{l}\text { 2015-2020: Funding by German Academic Exchange Service } \\
\text { sponsored by German Federal Ministry of Education and Research }\end{array}$ \\
\hline & & & Financial contributions of partners to mobility program \\
\hline 5. & Composition & $\begin{array}{l}11 \text { German HEIs incl. a team of ca. } 40 \text { researchers and practitioners } \\
\text { (HOCH-N project) backed by additional } 5 \text { HEIs and } 163 \\
\text { individuals from } 101 \text { German HEIs (HOCH-N network) }\end{array}$ & Ca. 30 Executive Board members, researchers and practitioners \\
\hline 6. & $\begin{array}{l}\text { Organizational structure \& } \\
\text { role of leadership }\end{array}$ & $\begin{array}{l}\text { Central management at Hamburg University and Bremen } \\
\text { University, supplemented by } 9 \text { other HEIs from HOCH-N project }\end{array}$ & $\begin{array}{l}\text { Central management at Freie Universität Berlin and project } \\
\text { coordinators at partner universities; strong support of university } \\
\text { leadership of all partners, anchored in Network Board }\end{array}$ \\
\hline 7. & Open/closed & $\begin{array}{l}\text { Open to new members from German HEIs, politics, industry, } \\
\text { and civil society; additional outreach to experts from international } \\
\text { HEI-networks for sustainability }\end{array}$ & $\begin{array}{l}\text { Closed; focused on the strategic partner universities of Freie } \\
\text { Universität Berlin with strong outreach activities in international } \\
\text { sustainability networks }\end{array}$ \\
\hline \multirow[b]{2}{*}{8.} & \multirow[b]{2}{*}{ Heterogeneity/homogeneity } & German (mother tongue) & English (working language, mother tongue for one member) \\
\hline & & $\begin{array}{l}\text { Stakeholders from research, teaching, governance, campus } \\
\text { management, transfer and reporting }\end{array}$ & $\begin{array}{l}\text { Stakeholders from research, teaching, transfer, management } \\
\text { and administration }\end{array}$ \\
\hline
\end{tabular}


Table 2. Cont

\begin{tabular}{|c|c|c|c|}
\hline & Characteristic & HOCH-N & UAS \\
\hline \multirow{4}{*}{9.} & \multirow{4}{*}{ Degree of formalization } & $\begin{array}{l}\text { HOCH-N project encompasses } 6 \text { working groups, each with an } \\
\text { interdisciplinary research team from two HEIs; supported by central } \\
\text { management and advisory board }\end{array}$ & $\begin{array}{l}\text { Clear governance structure consisting of Network Board, Steering } \\
\text { Committee and central network management, as well as } \\
\text { representatives and coordinators at each partner university }\end{array}$ \\
\hline & & $\begin{array}{l}\text { Network management rooted at sustainability-oriented research teams } \\
\text { of Hamburg and Bremen University involved in the } \mathrm{HOCH}-\mathrm{N} \text { project }\end{array}$ & $\begin{array}{l}\text { Network management anchored in the Unit for Sustainability and } \\
\text { Energy Management, which is directly assigned to the Executive } \\
\text { Board of Freie Universität Berlin }\end{array}$ \\
\hline & & $\begin{array}{l}\text { Research proposals for the HOCH-N project (phase I: 2016-2018 and } \\
\text { phase II: 2018-2020) incl. detailed milestones }\end{array}$ & $\begin{array}{l}\text { Mission statement; } \\
\text { Detailed milestones and measurement plans }\end{array}$ \\
\hline & & $\begin{array}{l}\text { HOCH-N network formalized by conditions of admission, joint } \\
\text { website and network map, regular meetings, workshops, } \\
\text { and newsletter }\end{array}$ & Network website and communication \\
\hline \multirow{8}{*}{10.} & \multirow{8}{*}{ Form(s) of collaboration } & \multirow{2}{*}{$\begin{array}{l}\text { Regular workshops among } 11 \text { HEIs from } \mathrm{HOCH}-\mathrm{N} \text { project, incl. } \\
\text { researchers, students and management staff from other HEIs }\end{array}$} & $\begin{array}{l}\text { Teaching and management incubators to trigger collaboration and } \\
\text { best practice exchange }\end{array}$ \\
\hline & & & $\begin{array}{l}\text { Annual conference in Berlin including research and management } \\
\text { related workshops, PhD conference }\end{array}$ \\
\hline & & \multirow{2}{*}{$\begin{array}{l}\text { Interdisciplinary, interinstitutional research, joint presentations at } \\
\text { national and international conferences, as well as joint development of } \\
\text { scientific publications and practical guides }\end{array}$} & $\begin{array}{l}\text { Mobility program for researchers, } \mathrm{PhD} \text { candidates, students, } \\
\text { and management staff for research and study stays }\end{array}$ \\
\hline & & & Additional bilateral workshops \\
\hline & & \multirow{2}{*}{$\begin{array}{l}\text { Regular teleconferencing among heads from } 6 \text { working groups and } \\
\text { central management }\end{array}$} & Exchange opportunities for student volunteer initiatives \\
\hline & & & Short-term lectureships; joint courses (virtual, blended or on-site) \\
\hline & & Shared data base among 11 HEIs & JI \\
\hline & & Website and newsletter & Vveosite \\
\hline \multirow[b]{2}{*}{11.} & \multirow{2}{*}{$\begin{array}{l}\text { Mode of interaction and } \\
\text { communication }\end{array}$} & Personally and virtually & \\
\hline & & Decentralized mode of interaction & $\begin{array}{l}\text { Mixed mode of interaction, central impulses, interaction patterns } \\
\text { of ripple effects }\end{array}$ \\
\hline 12. & Developmental stages & Transition between development stage and implementation stage & Implementation stage \\
\hline
\end{tabular}


Table 2. Cont

\begin{tabular}{|c|c|c|c|}
\hline & Characteristic & HOCH-N & UAS \\
\hline \multirow[t]{2}{*}{13.} & \multirow[t]{2}{*}{ Ethos } & $\begin{array}{l}\text { Joint trust, identity and strong commitment within HOCH-N project } \\
\text { gradually built via joint project goals, regular exchange and close } \\
\text { collaboration on joint products, such as practical guides and } \\
\text { scientific publications }\end{array}$ & \multirow{2}{*}{$\begin{array}{l}\text { Collaboration has grown incrementally, built on institutional and } \\
\text { personal contacts and trust; } \\
\text { Strong commitment and participation of leadership facilitates } \\
\text { whole institution approach }\end{array}$} \\
\hline & & $\begin{array}{l}\text { Up to now mostly loose ties in the greater HOCH-N network with } \\
\text { more intensive collaborations planned for } 2018-2020\end{array}$ & \\
\hline 14. & Context & $\begin{array}{l}\text { HOCH-N is linked to national efforts to implement the UNESCO } \\
\text { world action program, to efforts to adjust the sustainability codex } \\
\text { resolved by the German Council for Sustainable Development to the } \\
\text { context of HEIs, as well as to intentions of German HEIs to strengthen } \\
\text { exchange and collaboration toward sustainability. }\end{array}$ & $\begin{array}{l}\text { The UAS network was established from a joint understanding that } \\
\text { universities have a societal responsibility to contribute and shape } \\
\text { the global sustainability discourse. }\end{array}$ \\
\hline \multirow{7}{*}{15.} & \multirow{7}{*}{ Outcome } & Project goals and milestones largely reached on network and node-level & \\
\hline & & $\begin{array}{l}\text { Initiation of bi- and multilateral research collaborations among } 11 \\
\text { HEIs of HOCH-N project }\end{array}$ & $\begin{array}{l}\text { Numerous joint projects in research and teaching have emerged at } \\
\text { Freie Universität Berlin and at partner universities }\end{array}$ \\
\hline & & \multirow{2}{*}{$\begin{array}{l}6 \text { practical guides to implement sustainability in governance, research, } \\
\text { teaching, transfer, campus management and reporting of German HEIs }\end{array}$} & Intensified sustainability activities at Freie Universität Berlin \\
\hline & & & To date 240 participants \\
\hline & & $\begin{array}{l}\text { Joint understanding of sustainability among } 11 \text { HEIs of } \\
\text { HOCH-N project }\end{array}$ & \multirow{3}{*}{$\begin{array}{l}\text { Several additional impacts, e.g., the UAS has led to valuable } \\
\text { contacts and collaboration with other universities }\end{array}$} \\
\hline & & $\begin{array}{l}\text { Sustainability codex of German Council for Sustainable Development } \\
\text { adapted to context of HEIs }\end{array}$ & \\
\hline & & Scientific publications & \\
\hline
\end{tabular}




\section{Synthesis and Outlook}

This article addresses two objectives. On the one hand, we suggest an analytical framework that allows a more structured description of HEI networks (Table 1) and apply it to two exemplary HEI networks for sustainability (Table 2). On the other hand, we provide insights on how a single node within a network, namely a single university, can concretely contribute to and benefit from its membership in an HEI network for sustainability. In the following, we first discuss the conceptual and practical contribution, as well as the limitations and future developmental potential of the analytical framework. Subsequently, we discuss the lessons learned from the two exemplary HEI networks for sustainability-HOCH-N and UAS-and complement them with the outcome of the interactive workshop at the ISCN Conference 2018.

\subsection{An Analytical Framework to Facilitate Learning about Structures, Processes, and Outcomes of HEI Networks for Sustainability}

Networks are complex organizational and social entities. The 15 characteristics presented in this article offer an analytical framework to systematically describe and differentiate the structures, processes, and outcomes of HEI networks in general. Their applicability was tested in the context of two concrete early-stage HEI networks for sustainability. The characteristics help to highlight the essential features of each of the two networks. Furthermore, this structured representation of networks facilitates learning between different networks and utilizing potential complementarities. Learning enables improvement of the own network. Looking at the two case studies, HOCH-N could for instance benefit from the experiences of UAS related to the different instruments to foster HEI collaboration. The UAS network can benefit from the insights of the HOCH-N project and network in the area of sustainability-oriented research, teaching, and transfer. Secondly, as universities are often members or nodes of different networks, they can more strategically profit from them and use their complementarities if the network profiles are more transparent. Besides HOCH-N, Leuphana and Freie Universität Berlin are for instance both members of ISCN, which is also following a whole institution approach but with a stronger focus on campus structures and activities. This focus links to several activities of UAS and HOCH-N, yet are rather complementary in nature. Finally, characterizing the landscape of networks in a specific area can also help to create a network of networks, in which the different networking activities strategically complement one another so that both the single nodes but also the landscape of networks unfold their optimal potential with regard to their overarching goal, i.e., fostering sustainability. The characteristics have been derived from relevant scientific literature but make no claim to be complete. To validate the characteristics, it is necessary to apply them to further networks and to adapt and expand the framework accordingly. In the following, we will use the 15 characteristics to discuss lessons learned from the two case studies and complement them with the results from the interactive workshop at ISCN 2018.

\subsection{Lessons Learned from Both a Meta- and a Single-Node Perspective on Two Exemplary HEI Networks for Sustainability}

The juxtaposition of the two exemplary networks has made it clear that, while they share fundamental similarities regarding the characteristics \#2 subject, \#3 objective, \#5 composition (in terms of stakeholder groups involved) presented in Table 2, they also have different starting situations, reflected in the characteristics \#1 geographic scope, \#8 homogeneity versus heterogeneity, as well as \#14 political and procedural context. In the following, we will introduce commonalities and differences in lessons learned in an attempt to shed light on the overall question of this article on how strategic networking for sustainability can be facilitated from the node perspective of a single HEI-network member. 


\subsection{Governance}

Both networks work with a high degree of formalization (characteristic \#9, Table 2), in that they build clear governance structures, as well as define strategic goals and areas of activity. In both cases, a clear decision-making structure proved decisive to goal-oriented and effective communication. The leadership role is assigned to representatives of the executive boards of the member universities in both networks. This highlights two network functions. On the one hand Leuphana University Lüneburg and Freie Universität Berlin as node members utilize the political function, by forming innovative collaborative groups with a clear commitment (characteristic \#13 ethos, Table 2) to fostering sustainability not in one or two fields of action such as research or teaching but holistically $[6,8,19]$. At the same time, the network collaborations proved to be incentivizing for mapping and accelerating sustainability-oriented research (Leuphana) and teaching (Freie Universität) in their home institutions (\#15 outcome, Table 2).

The clearly defined subject and objective contributed to establishing a shared vision for the network and aligned the activities of the network members (\#2 and \#3). The guiding principle of the whole institution approach that shaped these two characteristics was well accepted and supported by all network members. However, the commitment to this principle does not mean that it has already been fully implemented in every member HEI. Both HOCH-N and UAS are characterized by a great diversity of members, ranging from pioneering universities to members with well-established sustainability strategies to beginners (\#5 composition). This asymmetry needs to be addressed transparently and balanced by a differentiated set of network instruments for mutual benefits.

\subsection{Instruments}

Common to both networks is a central network management (\#6 organizational structure and role of leadership), which is placed at one of the partner universities. Besides management and communication tasks, the coordinators record network activities, build databases about existing and potential contacts, and facilitate networking in regard to the overall strategic purpose of the network. The UAS network works with a milestone and measure plan whereas defined work packages are allocated among the six different working groups in the HOCH-N network (\#9 degree of formalization). In the initial phase, the focus was on taking stock. Workshops and bilateral exchange (personal and virtual) were the main forms of collaboration (\#10). In case of the UAS the focus was on sustainability-related activities in all areas of the university, as well as on mapping existing bilateral contacts. The working group research in the HOCH-N network concentrated on mapping sustainability-oriented research activities across German HEIs. This process was essential for establishing a stable operational working structure and ensuring successful build-up and upkeep of the network. The information function of the network is evident in the close collaboration facilitated in different but constant modes of interaction (\#11), which contributed to the rapid exchange of information among the network members, as well as at the node universities [19].

Most networks are constantly undergoing changes in composition. In case of $\mathrm{HOCH}-\mathrm{N}$, as an explicitly open network (\#7), this is especially true and can best be addressed by a transparent communication of the central network management. The eleven founding HEIs, who spearhead the different working groups (\#11 mode of interaction and communication), take on a special role here, as in the case of Leuphana University, new members were invited and introduced to the processes. These initial exchange and interaction opportunities formed a basis for incremental trust building, thus shaping the ethos of the network (\#13). The UAS network on the other hand focuses on deepening the ties with the strategic partner universities of Freie Universität Berlin (\#11). While the institutional composition remains (currently) constant, there was always a need for the renewal of relationships as a result of staff and organizational changes (\#12 developmental stages). These changes are quite significant for universities, in particular concerning their governance structure. Identity building measures, like the UAS mission statement, annual topics, strategic meetings in the starting period, and constant communication helped to address these challenges. In the international framework of the 
UAS, the communicative and intercultural competence of the network team is just as decisive for the success of the network.

\subsection{Outcome}

In order to keep-up and proceed effectively, e.g., to accelerate efforts for sustainability, HEI networks need to constantly provide attractive conditions for their members. Besides offering a professional and resilient network management, their members expect benefits for their own development. Participants from HOCH-N benefit from topic- and demand-specific networking with other university actors across Germany and receive early access to the contents of the research project. They gain visibility for their sustainability projects and can strengthen their sustainability-oriented reputation in the HOCH-N project and network. In the case of the UAS, the network offered members the opportunity to deepen the already existing partnerships in an important future field that has high integration potential due to its cross-cutting character. The joint efforts in research and teaching, as well as the exchange of best practices in campus management, makes the UAS an incubator for change at the respective home institutions. Additionally, UAS partners follow their transfer approach and strive to be a sustainability model for other universities. Both case studies provide exemplary insights in the political and psychological functions networks can unfold [19]. Network members find themselves amongst a group of like-minded HEI actors working towards similar goals and can form collaborative groups that are able to utilize leverage points at their home institution and beyond.

As pointed out in the results section, the network also contributed to the integration and networking of sustainability-oriented research and teaching at Freie Universität Berlin. The active engagement in the UAS network proved to be an innovative factor for the sustainability-oriented efforts at Freie Universität Berlin. This innovation function could be successful because it was based on a governance structure which ideally combined the UAS collaboration with the sustainability management at Freie Universität Berlin. Additionally, the numerous networking events facilitated peer-to peer learning and allowed participants to broaden their knowledge and acquire new skills $[1,18,20]$. This implicit skills function of the network has decisively contributed to the ability of stakeholders to implement innovative projects (\#15 outcome) [19].

The question of concrete benefits derived from network memberships was also posed during the interactive session of the ISCN workshop when participants discussed their expectations towards HEI-networks for sustainability. For them the overall prospect of network membership was to create new contacts, as well as to get inspiration for sustainability-related innovations at their own HEI. More specifically participants were expecting to exchange best practice examples and lessons learned.

\subsection{Outlook}

This article has outlined the strategic outcomes a node university can have on the development of a network, as well as the outcome a network can have on the sustainability strategy of a node university. For the outlook and future development potential of both networks we need to iterate that third-party funding was a necessary condition for the foundation of both. Including the subsequent funding it allows the networks to develop for four (HOCH-N) to six (UAS) years (\#4 resources). Once funding expires, both networks need to find sustainable modes of communication and interaction. The question of benefits for the participating HEI members will be of paramount importance. A roadmap needs to be jointly established as proposed in the UAS Future Lab format. Furthermore, the contributions of the stakeholder group of the ISCN workshop provide valuable recommendations. Participants identified leverage points to advance HEI-networks and to strategically use them to foster sustainability at their HEI. For the future advancement of existing HEI-networks, external feedback and internal peer-review procedures were suggested to allow self-reflection, as well as to secure quality standards and efficacy. Another recommendation was to strategically win HEIs with high international reputation as members for networks. On the individual HEI-level, participants suggested to particularly mind the multiplicity of exchange opportunities and to concentrate on active participation in selected networks. 
Despite the successes achieved during the development period, it will be a challenge for both the HOCH-N and the UAS network to secure their existence after the funding phase. Ultimately, the future of both networks depends on whether they succeed in proving and expanding their attractiveness for the participating universities. Moreover, both networks must also prove their indispensability in their respective political contexts. This will require not only feasibility studies in close coordination with existing network members, but also close feedback to the respective political actors and potential funding institutions.

\section{Conclusions}

This article presented conceptual and empirical insights into how single HEIs can support and benefit from being a node in an HEI network for sustainability. The analytical framework of 15 characteristics introduced in this article has proven to contribute to the structured description and analysis of two exemplary HEI networks for sustainability. It enables the specification of a network's purpose, as well as its structures, processes, context, and outcomes. The framework also shows that social networks are complex entities that require a conscious and targeted design process, as well as regular reflections on optimization potentials.

Furthermore, we derived a set of practice-oriented lessons learned from two case studies, as well as from an interactive workshop at the ISCN Conference 2018. From a meta-perspective on HEI networks for sustainability, we found: (i) The composition of actual members, applied modes of interaction, available resources, and proposed outcomes are crucial aspects that influence the attractivity of an HEI network for new members. (ii) Different network governance structures, clearly assigned and distributed roles, consensus-based decision-making, as well as reliable, circumspect network management proved to be decisive factors for successful and continued network operation.

From an integrated perspective on an HEI network and its single HEI nodes, we found: (iii) (Co-)founders need to clearly highlight the benefits of membership and active participation in order to attract members from the institutional to the individual level. Higher education institutions can significantly increase the positive outcomes of a network membership at their institution by systematically facilitating interinstitutional exchange, collaboration, and mutual learning among its relevant HEI actors. In this context, a key finding from the UAS network, for instance, was that interinstitutional exchange sparked inspiration and learning at Freie Universität Berlin and subsequently the network itself was used as a means to accelerate sustainability-oriented teaching activities at this university. (iv) Ensured financial support is key in the sensitive phase of a network's foundation and first development, often initiated by one or few HEIs. We hope that our analyses help HEIs to be even more strategic in their networking activities, and existing and emerging networks learn from and complement each other. Non-strategic networking runs the risk of wasting precious resources on the individual and the institutional level, yet functional collaboration in networks has the potential to substantially leverage the contribution of HEI to sustainable development.

Author Contributions: Conceptualization, J.K., D.J.L., K.R., A.W.; Methodology, J.K., D.J.L., K.R., A.W.; Data collection, J.K., K.R., A.W., D.J.L.; Data analysis, K.R., J.K., A.W., D.J.L.; Writing-original draft preparation, J.K., K.R., A.W., D.J.L.; Writing一review and editing, J.K., K.R., A.W., D.J.L.; Funding acquisition: D.J.L.

Funding: This research was conducted within the joint research project "Sustainability at Higher Education Institutions: develop - network - report $(\mathrm{HOCH}-\mathrm{N})$ " funded by the German Federal Ministry of Education and Research, FKZ 13NKE007F, as well as within the network "University Alliance for Sustainability" funded by the German Academic Exchange Service.

Acknowledgments: The authors would like to thank the journal Sustainability and the guest editors Julie Newman, Göran Finnveden, and Leendert Verhoef for the invitation to contribute to this Special Issue. We would also like to thank the two reviewers, Annika Weiser and Guido Caniglia, for their critical and constructive comments on earlier versions of this paper. Another thanks goes to Cathel Hutchison and Amy Newsom for language assistance. Furthermore, we thank the participants of the interactive workshop on "Strategic Networking for Sustainability: Insights from Research and Practice" at the 12th International Sustainable Campus Network Conference at KTH Royal Institute of Technology in Stockholm, 11-13 June 2018, for their active engagement and input on HEI-networks for sustainability. Judith Kahle and Daniel J. Lang would like to thank the German 
Federal Ministry of Education and Research (BMBF) for providing funding for the empirical research at Leuphana University, in the context of the joint research project "Sustainability at Higher Education Institutions: develop - network - report", as well as for the publication of this paper. On behalf of Freie Universität Berlin, Katrin Risch and Andreas Wanke would like to thank the German Academic Exchange Service (DAAD) for funding the "University Alliance for Sustainability" in the framework program "Strategic Partnerships and Thematic Networks" sponsored by the German Federal Ministry of Education and Research.

Conflicts of Interest: The authors declare no conflict of interests.

\section{References}

1. Caniglia, G.; Luederitz, C.; Groß, M.; Muhr, M.; John, B.; Withycombe Keeler, L.; von Wehrden, H.; Laubichler, M.; Wiek, A.; Lang, D. Transnational collaboration for sustainability in higher education: Lessons from a systematic review. J. Clean. Prod. 2017, 168, 764-779. [CrossRef]

2. O'Brien, K. Global environmental change II: From adaptation to deliberate transformation. Prog. Hum. Geogr. 2012, 36, 667-676. [CrossRef]

3. Van der Leeuw, S.; Wiek, A.; Harlow, J.; Buizer, J. How much time do we have? Urgency and rhetoric in sustainability science. Sustain. Sci. 2012, 7, 115-120. [CrossRef]

4. Withycombe Keeler, L.; Wiek, A.; Lang, D.J.; Yokohari, M.; van Breda, J.; Olsson, L.; Ness, B.; Morato, J.; Segalàs, J.; Martens, P.; et al. Utilizing international networks for accelerating research and learning in transformational sustainability science. Sustain. Sci. 2016, 11, 749-762. [CrossRef]

5. Crow, M.M. Organizing Teaching and Research to Address the Grand Challenges of Sustainable Development. BioScience 2010, 60, 488-489. [CrossRef]

6. Finnveden, G.; Egan, E.-D.; Sandberg, T.; Strömberg, E. A Holistic Approach for Integration of Sustainable Development in Education, Research, Collaboration and Operations. In Handbook of Theory and Practice of Sustainable Development in Higher Education; Leal Filho, W., Skanavis, C., do Paço, A., Rogers, J., Kuznetsova, O., Castro, P., Eds.; Springer International Publishing: Cham, Switzerland, 2017; pp. 287-303, ISBN 978-3-319-47888-3.

7. König, A.; Evans, J. Introduction: Experimenting for sustainable development? Living laboratories, social learning and the role of the university. In Regenerative Sustainable Development of Universities and Cities; König, A., Ed.; Edward Elgar Publishing: Cheltenham, UK, 2013; pp. 1-23, ISBN 978-1-78100-364-0.

8. Lozano, R.; Ceulemans, K.; Alonso-Almeida, M.; Huisingh, D.; Lozano, F.J.; Waas, T.; Lambrechts, W.; Lukman, R.; Hugé, J. A review of commitment and implementation of sustainable development in higher education: Results from a worldwide survey. J. Clean. Prod. 2015, 108, 1-18. [CrossRef]

9. Trencher, G.; Bai, X.; Evans, J.; McCormick, K.; Yarime, M. University partnerships for co-designing and co-producing urban sustainability. Glob. Environ. Chang. 2014, 28, 153-165. [CrossRef]

10. Verhoef, L.; Graamans, L.; Gioutsos, D.; van Wijk, A.; Geraedts, J.; Hellinga, C. ShowHow: A Flexible, Structured Approach to Commit University Stakeholders to Sustainable Development. In Handbook of Theory and Practice of Sustainable Development in Higher Education; Leal Filho, W., Azeiteiro, U.M., Alves, F., Molthan-Hill, P., Eds.; Springer International Publishing: Cham, Switzerland, 2017; pp. 491-508, ISBN 978-3-319-47876-0.

11. Wissenschaftlicher Beirat Globale Umweltveränderungen. Welt im Wandel: Gesellschaftsvertrag für eine Große Transformation. Hauptgutachten; 2., veränd. Aufl.; Wiss. Beirat der Bundesregierung Globale Umweltveränderungen (WBGU): Berlin, Germany, 2011; ISBN 978-3-936191-38-7.

12. Yarime, M.; Trencher, G.; Mino, T.; Scholz, R.W.; Olsson, L.; Ness, B.; Frantzeskaki, N.; Rotmans, J. Establishing sustainability science in higher education institutions: Towards an integration of academic development, institutionalization, and stakeholder collaborations. Sustain. Sci. 2012, 7, 101-113. [CrossRef]

13. Sustainability at Higher Education Institutions: Develop-Network-Report (HOCH-N). Available online: https:/ / www.hochn.uni-hamburg.de/en.html (accessed on 25 November 2018).

14. Bassen, A.; Schmitt, C.T.; Stecker, C. Nachhaltigkeit an Hochschulen: Entwickeln-vernetzen-berichten (HOCHN). uwf UmweltWirtschaftsForum 2017, 25, 139-146. [CrossRef]

15. Lang, D.J.; Wiek, A. The role of universities in fostering urban and regional sustainability. In Institutional and Social Innovation for Sustainable Urban Development, 1st ed.; Mieg, H.A., Töpfer, K., Eds.; Earthscan: London, UK, 2013; pp. 393-411, ISBN 978-1138780552. 
16. Stauffacher, M.; Flüeler, T.; Krütli, P.; Scholz, R.W. Analytic and Dynamic Approach to Collaboration: A Transdisciplinary Case Study on Sustainable Landscape Development in a Swiss Prealpine Region. Syst. Pract. Action Res. 2008, 21, 409-422. [CrossRef]

17. Borgatti, S.P.; Foster, P.C. The Network Paradigm in Organizational Research: A Review and Typology. J. Manag. 2003, 29, 991-1013. [CrossRef]

18. Rincón-Gallardo, S.; Fullan, M. Essential features of effective networks in education. J. Prof. Capital Commun. 2016, 1, 5-22. [CrossRef]

19. Sliwka, A. Networks of Innovation: Towards New Models for Managing Schools and Systems; Schooling for tomorrow (Project); Organisation for Economic Co-operation and Development, Centre for Educational Research and Innovation, Ed.; Organisation for Economic Co-operation and Development: Paris, France, 2003; pp. 49-63, ISBN 978-92-64-10034-3. Available online: https://www.oecd.org/site/ schoolingfortomorrowknowledgebase/themes/innovation/41283632.pdf (accessed on 15 October 2018).

20. Verburg, R.M.; Andriessen, E.H. A typology of knowledge sharing networks in practice. Knowl. Process Manag. 2011, 18, 33-44. [CrossRef]

21. International Association of Universities. Vision, Mission, Governance Structure, Annual Reports. Available online: https: / / www.iau-aiu.net/\# (accessed on 25 November 2018).

22. Association of African Universities. Vision, Mission, Our Strategic Goals, Our Strategy, Our Objectives. Available online: https:/ / www.aau.org/about/ (accessed on 25 November 2018).

23. Global University Network for Innovation. Background, Mission and objectives, Executive Committee. Available online: http:/ / www.guninetwork.org/presentation (accessed on 25 November 2018).

24. International Sustainable Campus Network. Organizational Structure, Purpose, Leadership. Available online: https://www.international-sustainable-campus-network.org/about/overview (accessed on 6 December 2018).

25. University Alliance for Sustainability. Available online: https//www.fu-berin.de/en/sites/uas/index.html (accessed on 25 November 2018).

26. Sabharwal, M.; Varma, R. Transnational Research Collaboration: Expatriate Indian Faculty in the United States Connecting with Peers in India. East Asian Sci. Technol. Soc. 2015, 9, 275-293. [CrossRef]

27. Coccia, M.; Wang, L. Evolution and convergence of the patterns of international scientific collaboration. Proc. Natl Acad. Sci. USA 2016, 113, 2057-2061. [CrossRef] [PubMed]

28. Caniglia, G.; John, B.; Bellina, L.; Lang, D.J.; Wiek, A.; Cohmer, S.; Laubichler, M.D. The glocal curriculum: A model for transnational collaboration in higher education for sustainable development. J. Clean. Prod. 2018, 171, 368-376. [CrossRef]

29. Sutrisno, A.; Hitendra, P. Knowledge transfer through a transnational program partnership between Indonesian and Australian universities. Asia Pac. Educ. Rev. 2015, 16, 379-388. [CrossRef]

30. Flick, U. Triangulation. Eine Einführung, 1st ed.; VS. Verlag für Sozialwissenschaften: Wiesbaden, Germany, 2004; pp. 27-48, ISBN 978-3531156668.

31. Boell, S.K.; Cecez-Kecmanovic, D. Are systematic reviews better, less biased and of higher quality? European Conference on Information Systems. 2011. (ECIS 2011), Paper 223. Available online: https: / /aisel.aisnet.org/ ecis2011/223/ (accessed on 21 November 2018).

32. Gehanno, J.-F.; Rollin, L.; Darmoni, S. Is the coverage of google scholar enough tob e used alone for systematic reviews. BMC Med. Inf. Decis. Mak. 2013, 13, 7. [CrossRef]

33. Martín-Martín, A.; Orduna-Malea, E.; López-Cózar, E.D. Coverage of highly-cited documents in Google Scholar, Web of Science, and Scopus: A multidisciplinary comparison. Scientometrics 2018, 116, 2175-2188. [CrossRef]

34. Mayring, P. Qualitative Inhaltsanalyse: Grundlagen und Techniken, 11th ed.; Weinheim and Basel: Beltz Verlag, Germany, 2010; pp. 48-66, ISBN 978-3-407-25533-4.

35. Corcoran, P.B.; Walker, K.E.; Wals, A.E.J. Case studies, make your case studies, and case stories: A critique of case study methodology in sustainability in higher education. Environ. Educ. Res. 2004, 10, 7-21. [CrossRef]

36. Gerring, J. Case Study Research: Principles and Practices; Cambridge University Press: Cambridge, UK, 2007; pp. 15-37, ISBN 9780521859288.

37. Yin, R.K. Case Study Research: Design and Methods, 3rd ed.; SAGE: Newcastle Upon Tyne, UK, 2003; pp. 1-116, ISBN 9780761925521. 
38. Getha-Taylor, H.; Silvia, C.; Simmerman, S. Individuality, Integrity: Leadership Styles in Team Collaboration. Public Manag. 2014, 43, 38-43.

39. Global Action Programme on Education for Sustainable Development. Available online: https://en.unesco. org/gap (accessed on 22 October 2018).

40. Kahle, J.; Jahn, S.; Lang, D.J.; Vogt, M.; Weber, C.F.; Lütke-Spatz, L.; Winkler, J. Nachhaltigkeit in der Hochschulforschung (Beta-Version). BMBF-Projekt "Nachhaltigkeit an Hochschulen: Entwickeln-berichten-vernetzen (HOCH-N)". Lüneburg/Munich, Germany. 2018. Available online: https:/ /www.hochn.uni-hamburg.de/ -downloads/handlungsfelder/forschung/hoch-n-leitfaden-nachhaltigkeit-in-der-hochschulforschung. pdf (accessed on 06 December 2018).

41. International Alliance of Research Universities (IARU). Green Guide for Universities; SUSTAINIA: Copenhagen, Danmark, 2014; pp. 6-139, ISBN 978-87-93038-21-9. Available online: http://www.iaruni.org/images/ stories/Sustainability/IARU_Green_Guide_for_Universities_2014.pdf (accessed on 06 December 2018).

2018 by the authors. Licensee MDPI, Basel, Switzerland. This article is an open access article distributed under the terms and conditions of the Creative Commons Attribution (CC BY) license (http:// creativecommons.org/licenses/by/4.0/). 